\title{
Heat and Mass Transfer in External Boundary Layer Flows Using Nanofluids
}

\author{
Catalin Popa, Guillaume Polidori, Ahlem Arfaoui and Stéphane Fohanno \\ Université de Reims Champagne-Ardenne, GRESPI/Thermomécanique (EA4301) \\ Moulin de la Housse, BP1039, 51687 Reims cedex 2,
}

France

\section{Introduction}

The application of additives to base liquids in the sole aim to increase the heat transfer coefficient is considered as an interesting mean for thermal systems. Nanofluids, prepared by dispersing nanometer-sized solid particles in a base-fluid (liquid), have been extensively studied for more than a decade due to the observation of an interesting increase in thermal conductivity compared to that of the base-fluid (Xuan \& Roetzel, 2000; Xuan \& Li, 2000). Initially, research works devoted to nanofluids were mainly focussed on the way to increase the thermal conductivity by modifying the particle volume fraction, the particle size/shape or the base-fluid (Murshed et al., 2005; Wang \& Mujumdar, 2007). Using nanofluids strongly influences the boundary layer thickness by modifying the viscosity of the resulting mixture leading to variations in the mass transfer in the vicinity of walls in external boundary-layer flows. Then, research works on convective heat transfer, with nanofluids as working fluids, have been carried out in order to test their potential for applications related to industrial heat exchangers. It is now well known that in forced convection (Maïga et al. 2005) as well as in mixed convection, using nanofluids can produce a considerable enhancement of the heat transfer coefficient that increases with the increasing nanoparticle volume fraction. As concerns natural convection, the fewer results published in the literature (Khanafer et al. 2003; Polidori et al., 2007; Popa et al., 2010; Putra et al. 2003) lead to more mixed conclusions. For example, recent works by Polidori et al. (2007) and Popa et al. (2010) have led to numerical results showing that the use of Newtonian nanofluids for the purpose of heat transfer enhancement in natural convection was not obvious, as such enhancement is dependent not only on nanofluids effective thermal conductivities but on their viscosities as well. This means that an exact determination of the heat transfer parameters is not warranted as long as the question of the choice of an adequate and realistic effective viscosity model is not resolved (Polidori et al. 2007, Keblinski et al. 2008). It is worth mentioning that this viewpoint is also confirmed in a recent work (Ben Mansour et al., 2007) for forced convection, in which the authors indicated that the assessment of the heat transfer enhancement potential of a nanofluid is difficult and closely dependent on the way the nanofluid properties are modelled. Therefore, the aim of this paper is to present theoretical models fully describing the natural and forced convective heat and mass transfer regimes for nanofluids flowing in semi-infinite geometries, i.e. external boundary layer flows along 
flat plates. In order to reach this goal, the integral formalism is extended to nanofluids. This work is the continuation of previous studies carried out to develop free and forced convection theories of external boundary layer flows by using the integral formalism (Polidori et al., 1999; Polidori et al., 2000; Polidori \& Padet, 2002; Polidori et al., 2003; Varga et al., 2004) as well as to investigate convective heat and mass transfer properties of nanofluids (Fohanno et al., 2010; Nguyen et al., 2009; Polidori et al., 2007; Popa et al., 2010) where both viscosity and conductivity analytical models have been used and compared with experimental data. The Brownian motion has also been taken into account. Nevertheless these studies focused mainly heat transfer. Free and forced convection theories have been developed both in the laminar and turbulent regimes and applied to conventional fluids such as water and air. Application of the integral formalism to nanofluids has been recently proposed in the case of laminar free convection (Polidori et al., 2007; Popa et al. 2010).

In order to develop these models, nanofluids will be considered flowing in the laminar regime over a semi-infinite flat plate suddenly heated with arbitrary heat flux densities. The laminar flow regime in forced and natural convection is investigated for Prandtl numbers representative of nanofluids. The nanofluids considered for this study, at ambient temperature, are water-alumina and water- $\mathrm{CuO}$ suspensions composed of solid alumina nanoparticles with diameter of $47 \mathrm{~nm}\left(\rho_{\mathrm{p}}=3880 \mathrm{~kg} / \mathrm{m}^{3}\right)$ and solid copper oxide nanoparticles with diameter of $29 \mathrm{~nm}\left(\rho_{\mathrm{p}}=6500 \mathrm{~kg} / \mathrm{m}^{3}\right)$ with water as base-fluid. The thermophysical properties of the nanofluids are obtained by using empirical models based on experimental data for computing viscosity and thermal conductivity of water-alumina and water-CuO suspensions, and based on a macroscopic modelling for the other properties. The influence of the particle volume fraction is investigated in the range $0 \% \leq \phi \leq 5 \%$.

The chapter is organized as follows. First, the development of the integral formalism (Karman Pohlhausen approach) for both types of convection (free and forced) in the laminar regime is provided in Section 2. Then, Section 3 details a presentation of nanofluids. A particular attention is paid on the modelling of nanofluid thermophysical properties and their limitations. Section 4 is devoted to the application of the theoretical models to the study of external boundary-layer natural and forced convection flows for the two types of nanofluids. Results are presented for particle volume fractions up to $5 \%$. Results on the flow dynamics are first provided in terms of velocity profiles, streamlines and boundary layer thickness. Heat transfer characteristics are then presented by means of wall temperature distribution and convective heat transfer coefficients.

\section{Mathematical formulation}

\subsection{Natural convection}

Consider laminar free convection along a vertical plate initially located in a quiescent fluid under a uniform heat flux density thermal condition. Denote $U$ and $V$ respectively the velocity components in the streamwise $x$ and crosswise $y$ directions. Assuming constant fluid properties and negligible viscous dissipation (Boussinesq's approximations) the continuity, boundary-layer momentum and energy equations are:

Continuity equation:

$$
\frac{\partial U}{\partial x}+\frac{\partial V}{\partial y}=0
$$


Momentum equation:

$$
U \frac{\partial U}{\partial x}+V \frac{\partial U}{\partial y}=g \beta\left(T_{w}-T_{\infty}\right)+\vartheta \frac{\partial^{2} U}{\partial y^{2}}
$$

Energy equation:

$$
U \frac{\partial T}{\partial x}+V \frac{\partial T}{\partial y}=\frac{\vartheta}{P r} \frac{\partial^{2} T}{\partial y^{2}}
$$

Using the Karman-Pohlhausen integral method (Kakaç and Yener, 1995 ; Padet, 1997), physically polynomial profiles of fourth order are assumed for flow velocity and temperature across the corresponding hydrodynamic and thermal boundary layers (see Figure 1). The major advantage in using such a method is that the resulting equations are solved anatically.
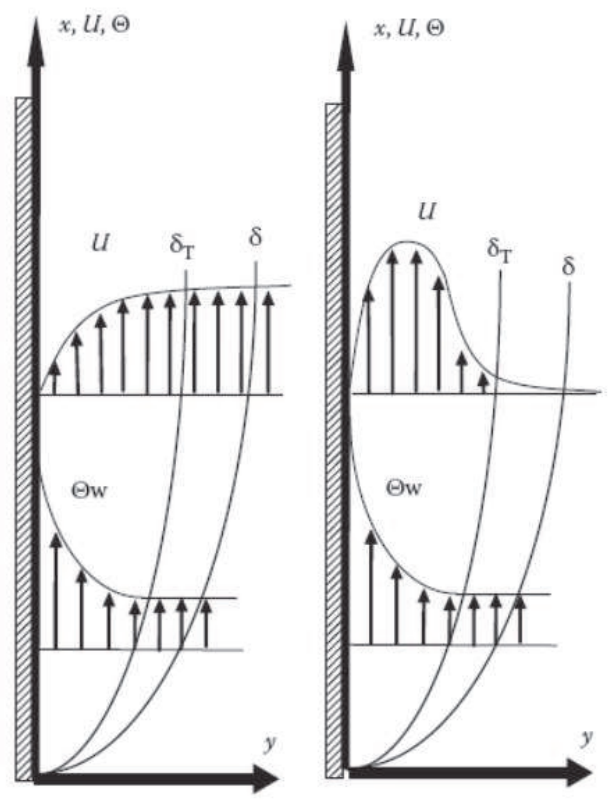

Fig. 1. Schematization of external boundary layer flows in forced convection (left) and free convection (right)

The method of analysis assumes that the velocity and temperature distributions have temporal similarity (Polidori et al., 2000) meaning that the ratio $\Delta$ between the temperature $\delta_{T}$ and the velocity $\delta$ layers depends only upon the Prandtl number.

$$
\Delta=\frac{\delta_{T}}{\delta}
$$

Thus, combining relation (4), the Fourier's law and adequate boundary conditions leads to the following $U$-velocity and $\Theta$ temperature polynomial distributions depending mainly upon the $\delta$ dynamical parameter: 


$$
\begin{gathered}
U=\frac{g \beta \varphi_{w} \Delta \delta^{3}}{12 k \vartheta}\left(-\eta^{4}+3 \eta^{3}-3 \eta^{2}+\eta\right) \\
\Theta=T-T_{\infty}=\frac{\varphi_{w} \Delta \delta}{2 k}\left(-\eta_{T}^{4}+2 \eta_{T}^{3}-2 \eta_{T}+1\right)
\end{gathered}
$$

Where $\eta=\frac{y}{\delta} \leq 1, \eta_{T}=\frac{y}{\delta_{T}} \leq 1, \beta$ is the volumetric coefficient of thermal expansion, $\mathrm{k}$ is the thermal conductivity of the fluid, $\vartheta$ is the fluid kinematic viscosity, and $\varphi_{\mathrm{w}}$ is the heat flux density.

With the correlation (4), the integral forms of the boundary-layer momentum and energy conservation equations become :

$$
\begin{gathered}
\frac{\partial}{\partial x} \int_{0}^{\delta} U^{2} d y=g \beta \frac{\partial}{\partial x} \int_{0}^{\delta_{T}} \Theta d y-\vartheta\left(\frac{\partial \mathrm{U}}{\partial y}\right)_{y=0} \\
\frac{\partial}{\partial x} \int_{0}^{\delta_{T}} \Theta U d y=-\frac{\vartheta}{P r}\left(\frac{\partial \Theta}{\partial y}\right)_{y=0}
\end{gathered}
$$

The analytical resolution of the system (Eq. 7 and Eq. 8) leads to the knowledge of the boundary layer ratio $\Delta$ (Polidori et al., 2000) and on the other hand gives the steady evolution of the asymptotical $\delta$ solution.

Thus, introducing the parameter $K=\ln (P r)$, the evolution of the ratio $\Delta(P r)$ is found to be suitable whatever $\operatorname{Pr}>0.6$ and satisfactorily approached with the following relation :

$$
\Delta=1.576 \times 10^{-4} K^{4}-4.227 \times 10^{-3} K^{3}+4.282 \times 10^{-2} K^{2}-0.1961 K+0.901
$$

The asymptotical limit of the dynamical boundary layer thickness is analytically expressed as :

$$
\delta(x)=\Omega x^{\frac{1}{5}}
$$

where

$$
\Omega=\left[\frac{432 k \vartheta^{2}}{g \beta \varphi_{w} \Delta}(9 \Delta-5)\right]^{\frac{1}{5}}
$$

The best way to understand how the mass transfer occurs and how the boundary layer is feeded with fluid is to access the paths following by the fluid from the streamline patterns. For this purpose, let introduce a stream function $\Psi(\mathrm{x}, \mathrm{y})$ such that $\frac{\partial \Psi}{\partial y}=U$ and $\frac{\partial \Psi}{\partial x}=\int_{0}^{y} \frac{\partial U}{\partial x} d y$ with the condition $\Psi(x, 0)=0$ so that the continuity equation (1) is identically satisfied. The analytical resolution leads to the following steady state solution :

$$
\begin{gathered}
\Psi(x, y, t \rightarrow \infty)=\frac{g \beta \varphi_{w} \Delta}{12 k \vartheta}\left(-\frac{1}{5 \Omega} y^{5} x^{-\frac{1}{5}}+\frac{3}{4} y^{4}-\Omega y^{3} x^{\frac{1}{5}}+\frac{\Omega^{2}}{2} y^{2} x^{\frac{2}{5}}\right) \\
\Theta_{w}=T_{w}-T_{\infty}=\left[\frac{27 \varphi_{w}^{4} \vartheta^{2} \Delta^{4}}{2 g \beta k^{4}}(9 \Delta-5) x\right]^{\frac{1}{5}}
\end{gathered}
$$

Newton's law:

$$
\mathrm{h}=\frac{\varphi_{w}}{\Theta_{w}}
$$




\subsection{Forced convection}

The schematization of the forced convection physical problem is seen in Figure 1. The mathematical approach is based on the energy semi-integral equation resolution within the thermal boundary layer, by using the Karman-Pohlhausen method applied to both velocity and temperature flow fields.

$$
\frac{\partial}{\partial x} \int_{0}^{\delta_{T}} \Theta U d y=-\frac{v}{P r}\left(\frac{\partial \Theta}{\partial y}\right)_{y=0}
$$

The determination of the $\Delta$ ratio (steady relative thickness of both thermal and dynamical boundary layers) is made from the resolution of the steady form of the energy equation (Padet, 1997) from which it is shown that this parameter appears to be only fluid Prandtl number dependent. The resulting equation in the Prandtl number range covering the main usual fluids, namely $\operatorname{Pr}>0.6$, is written as :

$$
\frac{\Delta^{6}}{180}-\frac{3 \Delta^{5}}{140}+\frac{2 \Delta^{3}}{15}-\frac{37}{630 P r}=0
$$

Using the $4^{\text {th }}$ order Pohlhausen method with convenient velocity and thermal boundary conditions leads to the following velocity and temperature profiles :

$$
\begin{gathered}
U=U_{\infty}\left(\eta^{4}-2 \eta^{3}+2 \eta\right) \\
\Theta=\Theta_{w}\left(-\eta_{T}^{4}+2 \eta_{T}^{3}-2 \eta_{T}+1\right)
\end{gathered}
$$

These profiles are directly used to define dynamical parameters qualifying both heat and mass transfer, such as the dynamical boundary layer thickness $(\delta(x))$ and the thermal flow rate $\left(Q_{t h}\right)$ defined as follows :

$$
\begin{gathered}
\delta(x)=\sqrt{\frac{1260}{37}} \frac{x}{\sqrt{R e_{x}}} \\
Q_{t h}=\rho C_{p} \int_{0}^{\eta_{T}} \Theta U d y
\end{gathered}
$$

In such a case, the convective heat transfer coefficient is expressed as :

$$
h(x)=\frac{2}{\Delta \delta(x)}=\sqrt{\frac{37}{315 \Delta^{2}}} \frac{\sqrt{R e_{x}}}{x}
$$

\section{Thermophysical properties of nanofluids}

The thermophysical properties of the nanofluids, namely the density, volume expansion coefficient and heat capacity have been computed using classical relations developed for a two-phase mixture (Pak and Cho, 1998 ; Xuan and Roetzel, 2000 ; Zhou and Ni, 2008):

$$
\begin{gathered}
\rho_{n f}=(1-\phi) \rho_{b f}+\phi \rho_{p} \\
\beta_{n f}=(1-\phi) \beta_{b f}+\phi \beta_{p} \\
\left(\rho C_{p}\right)_{n f}=(1-\phi)\left(\rho C_{p}\right)_{b f}+\phi\left(\rho C_{p}\right)_{p}
\end{gathered}
$$


It is worth noting that for a given nanofluid, simultaneous measurements of conductivity and viscosity are missing. In the present study, on the basis of statistical nanomechanics, the dynamic viscosity is obtained from the relationship proposed by Maïga et al. 2005, 2006 for water- $\gamma \mathrm{Al}_{2} \mathrm{O}_{3}$ nanofluid (Eq. 25):

$$
\mu_{n f}=\mu_{b f}\left(123 \phi^{2}+7.3 \phi+1\right)
$$

and Nguyen et al., 2007 for water-CuO nanofluid (Eq. 26), and derived from experimental data:

$$
\mu_{n f}=\mu_{b f}\left(0.009 \phi^{3}+0.051 \phi^{2}-0.319 \phi+1.475\right)
$$

Most recently, Mintsa et al. 2009 proposed the following correlation based on experimental data for the water- $\gamma \mathrm{Al}_{2} \mathrm{O}_{3}$ nanofluid (Eq. 27)

$$
k_{n f}=k_{b f}(1.72 \phi+1.0)
$$

and for the water-CuO nanofluid (Eq. 28):

$$
k_{n f}=k_{b f}(1.74 \phi+0.99)
$$

\begin{tabular}{|c|c|c|c|c|c|}
\hline $\begin{array}{c}\text { Volume } \\
\text { fraction }\end{array}$ & $\rho$ & $c_{\mathrm{p}}$ & $\mu$ & $\beta$ & $\mathrm{k}$ \\
\hline$\%$ & $\frac{\mathrm{kg}}{\mathrm{m}^{3}}$ & $\frac{\mathrm{J}}{\mathrm{kg} \cdot \mathrm{K}}$ & $\frac{\mathrm{kg}}{\mathrm{m} \cdot \mathrm{s}}$ & $\frac{1}{K}$ & $\frac{W}{\mathrm{~m} . K}$ \\
\hline 0 & 998.2 & 4182 & $1.002 \mathrm{E}-03$ & $2.060 \mathrm{E}-04$ & 0.600 \\
\hline 1 & 1053.22 & 3971.61 & $1.218 \mathrm{E}-03$ & $2.040 \mathrm{E}-04$ & 0.604 \\
\hline 2 & 1108.24 & 3782.11 & $1.115 \mathrm{E}-03$ & $2.020 \mathrm{E}-04$ & 0.615 \\
\hline 3 & 1163.25 & 3610.54 & $1.222 \mathrm{E}-03$ & $2.000 \mathrm{E}-04$ & 0.625 \\
\hline 4 & 1218.27 & 3454.46 & $1.594 \mathrm{E}-03$ & $1.980 \mathrm{E}-04$ & 0.636 \\
\hline 5 & 1273.29 & 3311.87 & $2.285 \mathrm{E}-03$ & $1.960 \mathrm{E}-04$ & 0.646 \\
\hline
\end{tabular}

Table 1. Thermophysical properties of $\mathrm{CuO} /$ water nanofluid

\begin{tabular}{|c|c|c|c|c|c|}
\hline $\begin{array}{c}\text { Volume } \\
\text { fraction }\end{array}$ & $\rho$ & $c_{\mathrm{p}}$ & $\mu$ & $\beta$ & $\mathrm{k}$ \\
\hline$\%$ & $\frac{\mathrm{kg}}{\mathrm{m}^{3}}$ & $\frac{J}{\mathrm{Kg} \cdot K}$ & $\frac{\mathrm{kg}}{\mathrm{m} \cdot \mathrm{s}}$ & $\frac{1}{K}$ & $\frac{W}{\mathrm{~m} . K}$ \\
\hline 0 & 998.2 & 4182 & $1.002 \mathrm{E}-03$ & $2.060 \mathrm{E}-04$ & 0.600 \\
\hline 1 & 1027.02 & 4053.21 & $1.087 \mathrm{E}-03$ & $2.042 \mathrm{E}-04$ & 0.610 \\
\hline 2 & 1055.84 & 3931.45 & $1.198 \mathrm{E}-03$ & $2.024 \mathrm{E}-04$ & 0.621 \\
\hline 3 & 1084.65 & 3816.16 & $1.332 \mathrm{E}-03$ & $2.005 \mathrm{E}-04$ & 0.631 \\
\hline 4 & 1113.47 & 3706.84 & $1.492 \mathrm{E}-03$ & $1.987 \mathrm{E}-04$ & 0.641 \\
\hline 5 & 1142.29 & 3603.03 & $1.676 \mathrm{E}-03$ & $1.969 \mathrm{E}-04$ & 0.652 \\
\hline
\end{tabular}

Table 2. Thermophysical properties of Alumina / water nanofluid 


\section{Results}

To ensure laminar conditions for both the forced convection and the free convection problems, the imposed initial conditions have been respectively $\varphi_{w}=100 \mathrm{~W} / \mathrm{m}^{2}$ for the heat flux density in free convection and $\varphi_{w}=1000 \mathrm{~W} / \mathrm{m}^{2} ; U=1 \mathrm{~m} / \mathrm{s}$ for the heat flux density and external flow in forced convection.

\subsection{Natural convection velocity}

First, to analyse how the mass transfer occurs using nanofluids in thermal convection regimes, we have focused the following parameters:

- Velocity boundary layer thickness,

- Velocity profiles within the boundary layer,

- Streamline patterns,

Because nanofluids are mainly used in hydrodynamics to enhance the heat transfer and because in free convection the thermal and dynamical problems and conditions are coupled together, we have also focused :

- Temperature profiles in the thermal boundary layer,

- Heat transfer coefficient at wall,

- Thermal flow rate.

In figures 2 and 3 are presented the steady velocity boundary layer thickness along the wall, for the two tested nanofluids (Alumina/water and $\mathrm{CuO} /$ Water), in the range of Newtonian behaviour nanofluid (Fohano et al., 2010), namely for small values of particle volume fraction $\phi<5 \%$.

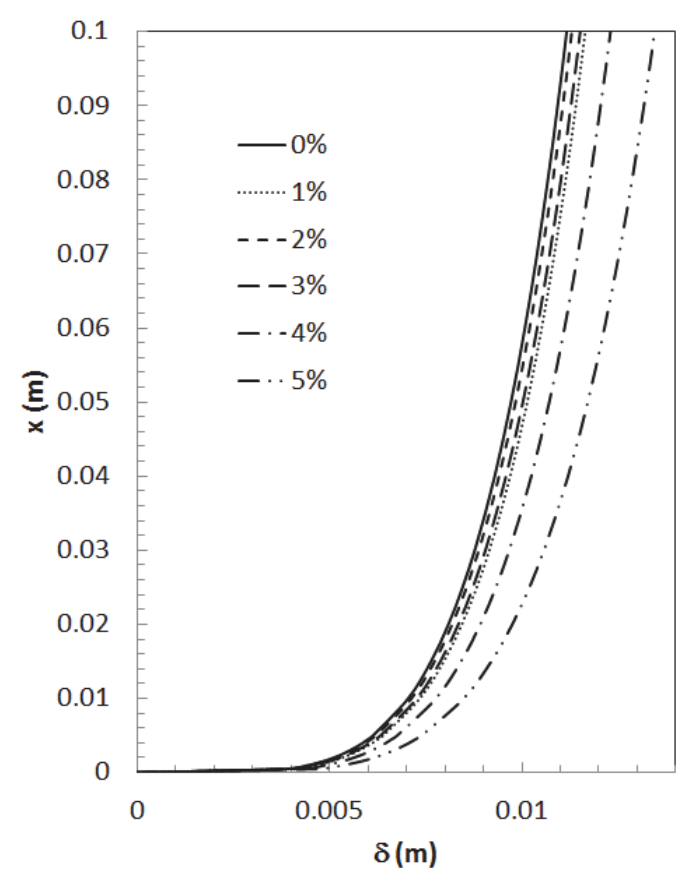

Fig. 2. Velocity boundary layer for $\mathrm{CuO} /$ water nanofluid 


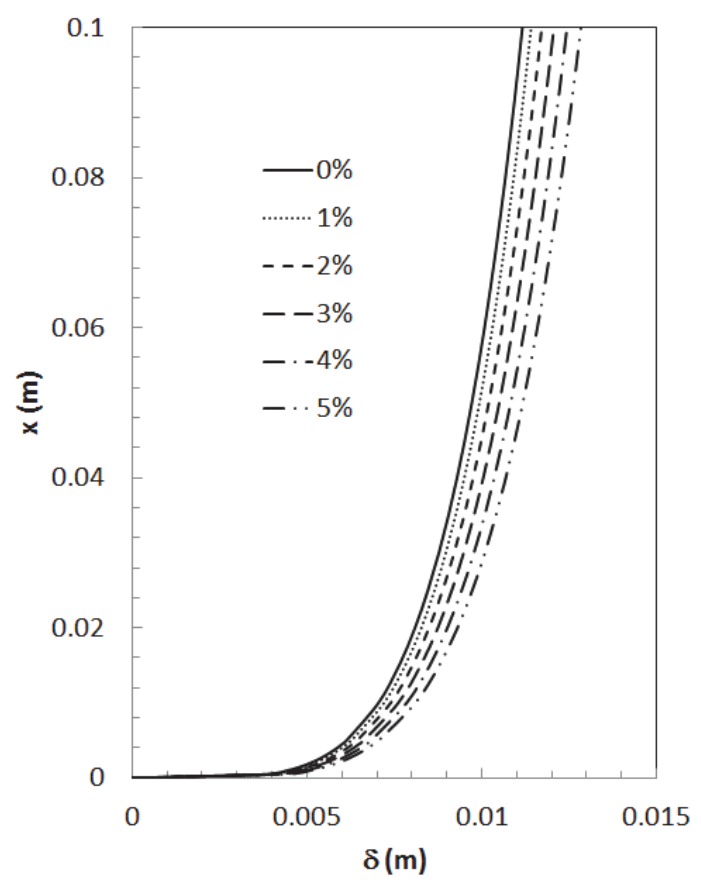

Fig. 3. Velocity boundary layer for Alumina / water nanofluid

Because varying the particle volume fraction highly influences the viscosity of the mixture, one can clearly see the resulting variation in thickness of the viscous boundary layer. Whatever the nanofluid is, an augmentation of the particle volume fraction value induces a higher thickness of the velocity boundary layer. Nevertheless, this phenomenon is more pronounced for the $\mathrm{CuO} /$ water nanofluid than for the alumina/water mixture, because the variation reaches respectively $22 \%$ and $16 \%$ at $\phi=5 \%$ in comparison with the reference case (base fluid only).

The velocity profiles within the velocity boundary layer are drawn in Figures 4 and 5 at a given $x=0.1 \mathrm{~m}$ abscissa, in the same range of particle volume fraction less than $5 \%$.

One observes similar trends whatever the nanofluid is :

- Flattening of the velocity profiles with the increase of the particle volume fraction,

- Modification in space of the location of the maximum velocity, following the evolution of the boundary layer thickness,

- Presence of a singular point, at the intersection of the profiles.

Focusing the volumetric flow rate leads to introduce a new parameter, called $\varepsilon$ defined as follows:

$$
\varepsilon=\left(\frac{Q_{v_{n f}}}{Q_{v_{b f}}}-1\right) * 100
$$




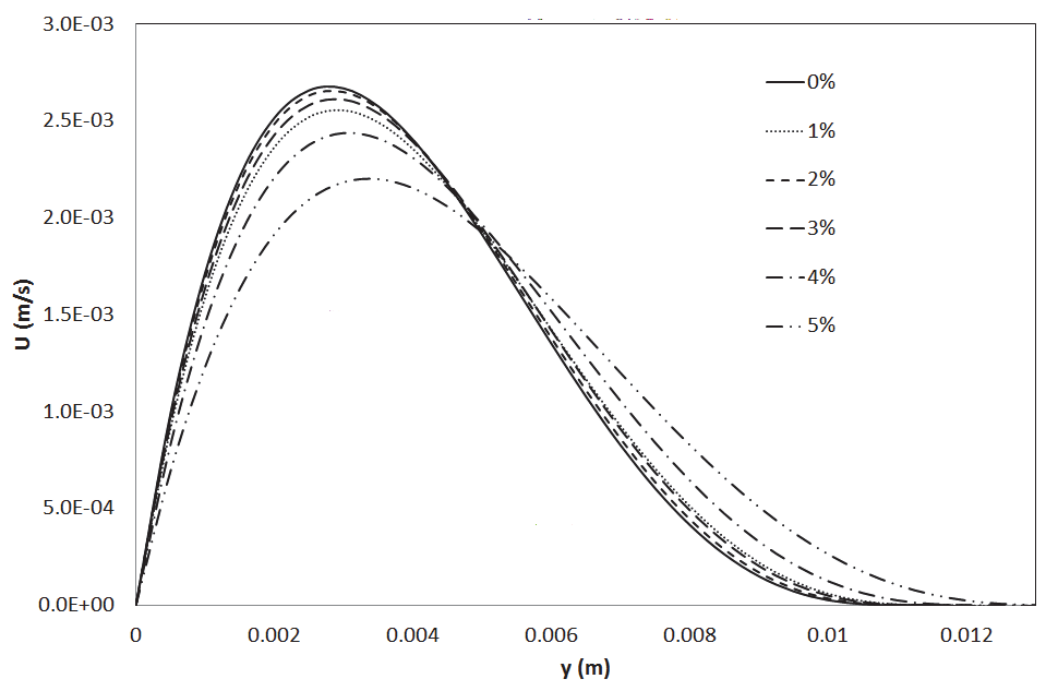

Fig. 4. Velocity profiles at $\mathrm{x}=0.1 \mathrm{~m}$ abscissa for $\mathrm{CuO} /$ water nanofluid

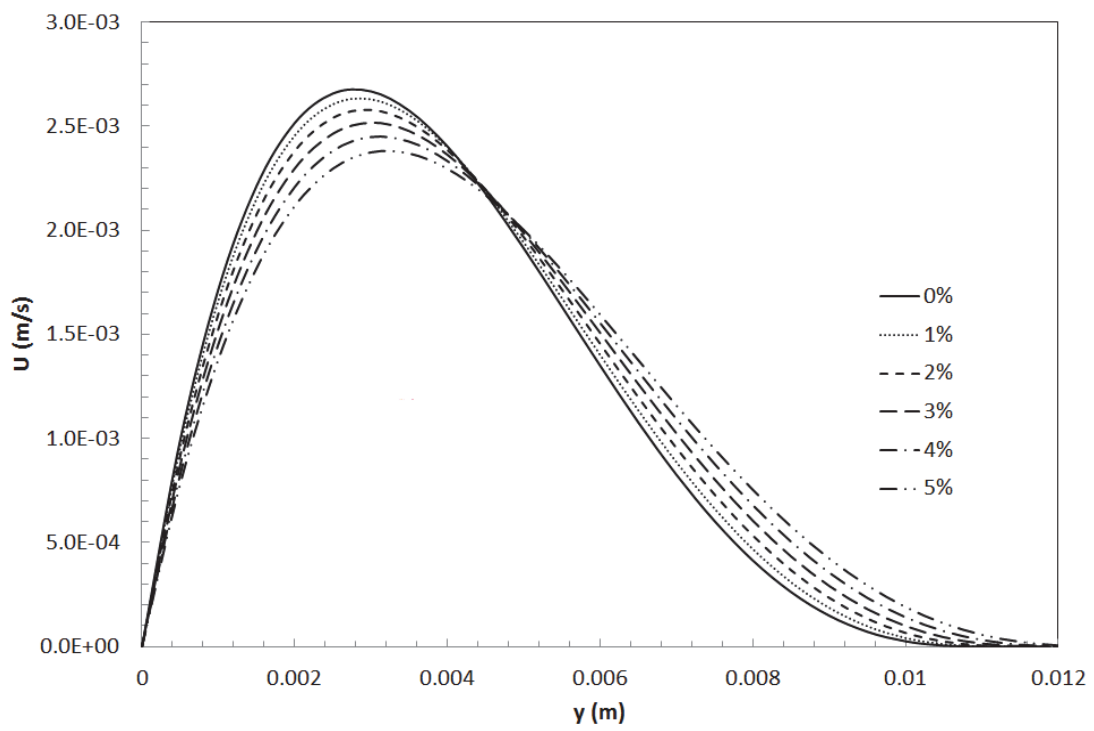

Fig. 5. Velocity profiles at $x=0.1 \mathrm{~m}$ abscissa for Alumina / water nanofluid

Table 3 summarizes the evolution of this parameter with the particle volume fraction, for both nanofluids. It clearly appears that the volumetric flow rate is no $\phi$ dependent, traducing conservation trend for the flow rate. Indeed, the volumetric flow rate for the mixture is close to that of the base fluid, not exceeding a $1 \%$ value. The boundary layer ratio $\Delta$ is also mentioned in Table 3. 


\begin{tabular}{|c|c|c|c|c|c|c|}
\hline & \multicolumn{2}{|c|}{$\mathrm{CuO} /$ water nanofluid } & \multicolumn{2}{c|}{ Alumina / water nanofluid } \\
\hline $\begin{array}{c}\text { Volume } \\
\text { fraction } \\
(\%)\end{array}$ & $\operatorname{Pr}$ & $\Delta$ & $\varepsilon$ & $\operatorname{Pr}$ & $\Delta$ & $\varepsilon$ \\
\hline 0 & 6.984 & 0.653 & $0.00 \%$ & 6.984 & 0.653 & $0.00 \%$ \\
\hline 1 & 8.006 & 0.643 & $-0.11 \%$ & 7.222 & 0.650 & $0.00 \%$ \\
\hline 2 & 6.860 & 0.654 & $0.34 \%$ & 7.586 & 0.647 & $0.44 \%$ \\
\hline 3 & 7.058 & 0.652 & $0.70 \%$ & 8.058 & 0.643 & $0.51 \%$ \\
\hline 4 & 8.662 & 0.638 & $0.83 \%$ & 8.623 & 0.638 & $0.55 \%$ \\
\hline 5 & 11.709 & 0.621 & $0.10 \%$ & 9.267 & 0.634 & $0.59 \%$ \\
\hline
\end{tabular}

Table 3. Nanofluids properties in natural convection

To complete this dynamical analysis, the streamline patterns are plotted in Figures 6 and 7 versus the y-direction. These streamline patterns are plotted for two particle volume fractions ( $2 \%$ and $5 \%)$ and are compared to a base fluid $(0 \%)$. The observed phenomena are similar for both nanofluids (CuO/water and Alumina/water).

The conclusion extracted from Figures 6 and 7 are that the mass flow has an intense upward motion close to the wall $(y=0)$ while the viscous layer is mainly fed with fluid coming from the crosswise direction from the wall.
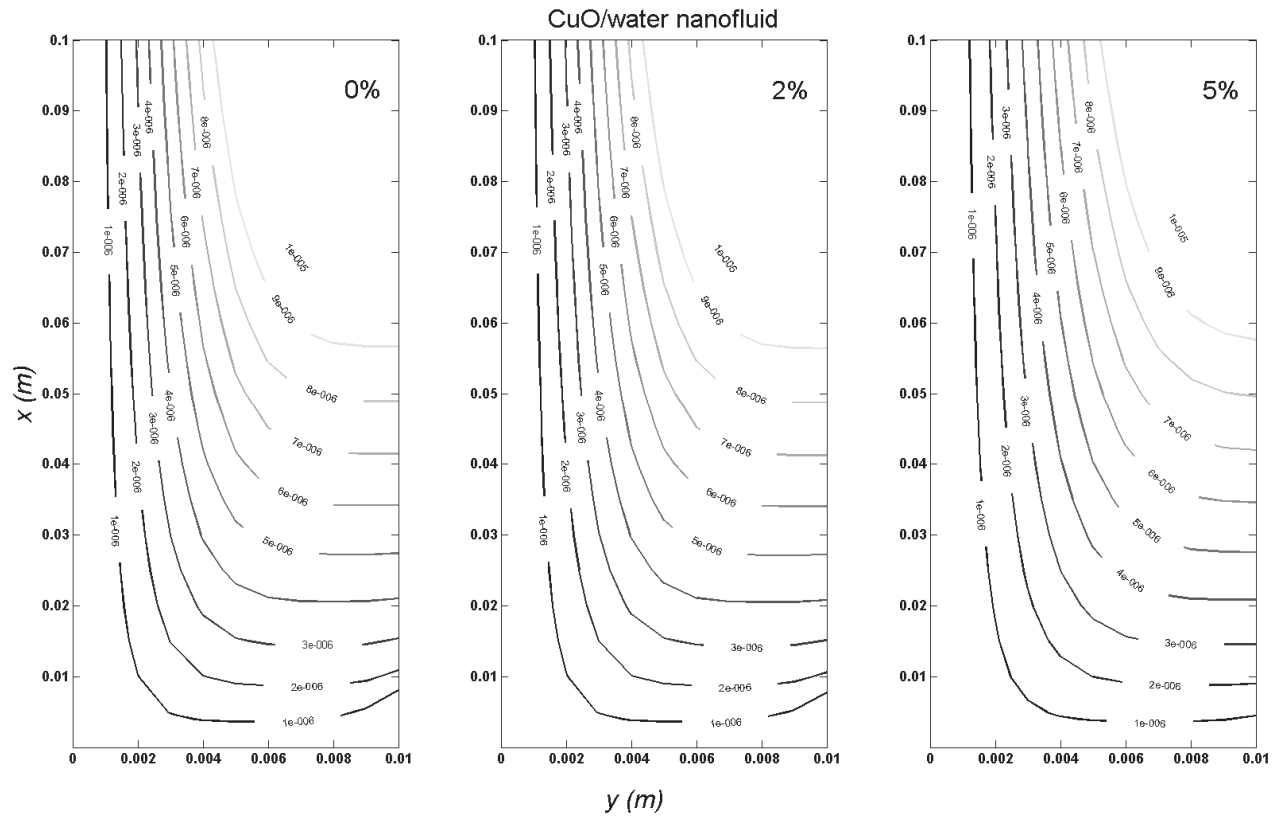

Fig. 6. Streamline patterns within the dynamic boundary layer for $\mathrm{CuO} /$ water nanofluid 

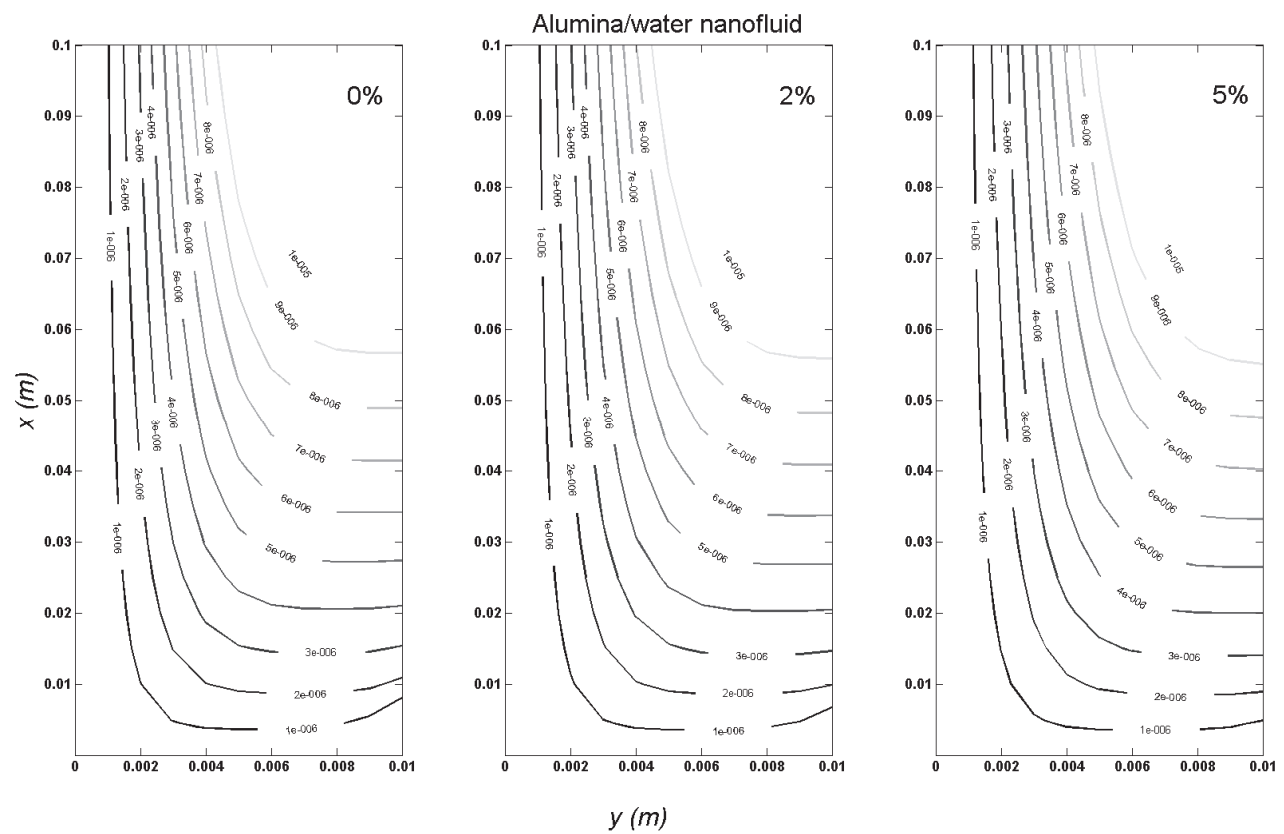

Fig. 7. Streamline patterns within the dynamic boundary layer for Alumina / water nanofluid

To make the analysis of such convection problems more complete, and because free convection induces the coupling of thermal and dynamical features of the flow, we present in Figures 8 and 9, the temperature profiles within the thermal boundary layers at a given abscissa $(x=0.1 \mathrm{~m})$.

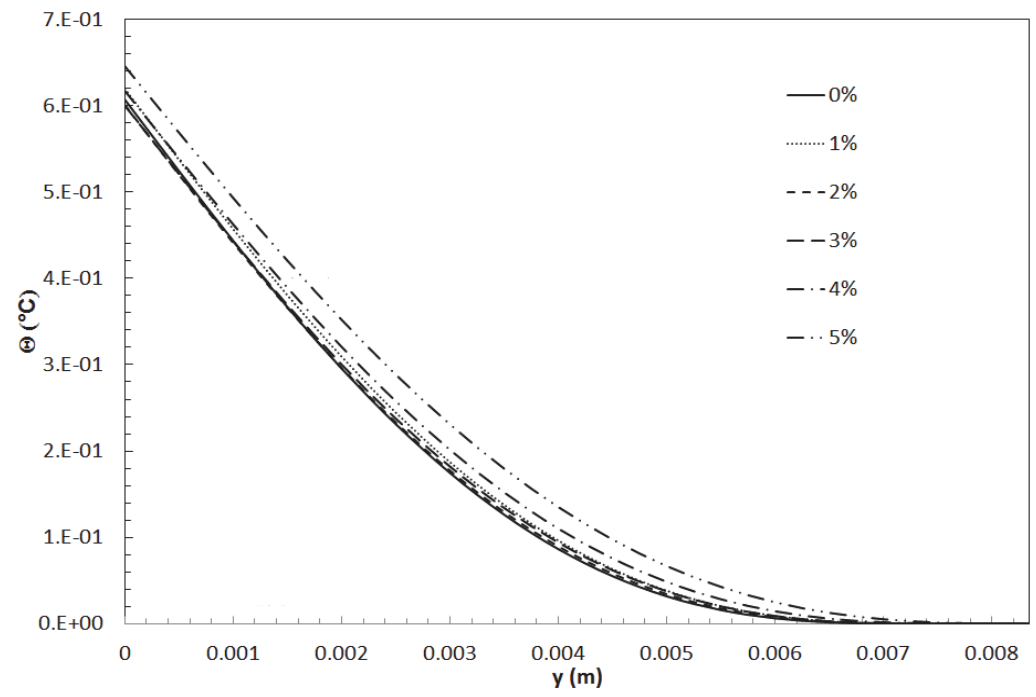

Fig. 8. Temperature profiles at $\mathrm{x}=0.1 \mathrm{~m}$ abscissa for $\mathrm{CuO} /$ water nanofluid 


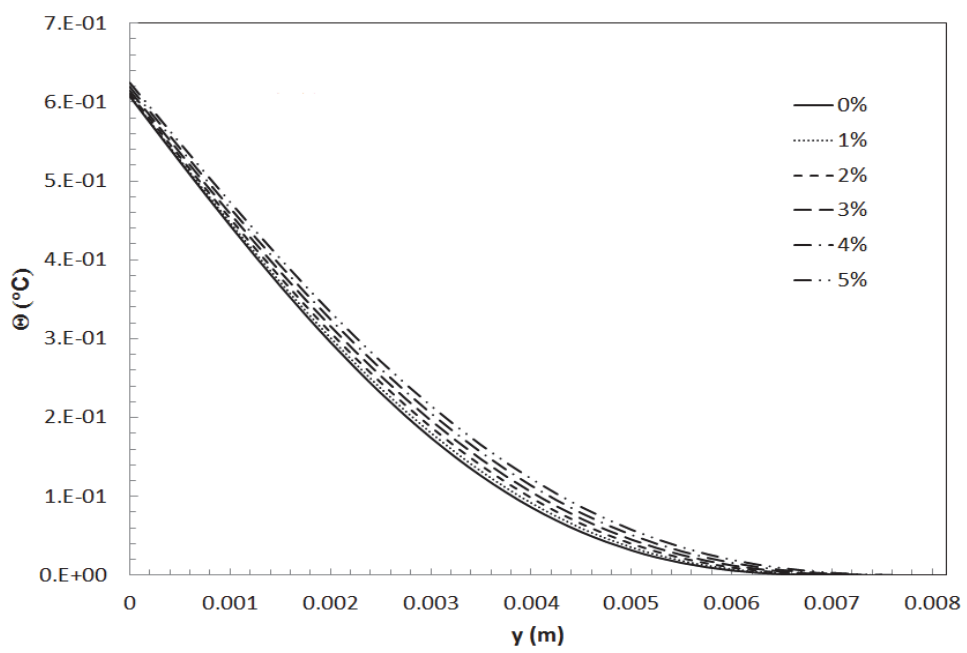

Fig. 9. Temperature profiles at $\mathrm{x}=0.1 \mathrm{~m}$ abscissa for Alumina / water nanofluid

There are no major differences between the temperature profiles for the two nanofluids. The common trend is that the increase of the particle volume fraction leads to increase the temperature at wall and within the thermal boundary layer whose thickness also increases compared to that of the base fluid.

The resolution of a heat transfer problem between a fluid and a wall often requires the knowledge of the heat transfer coefficient, called " $h$ ", which depends as the flow dynamic features as on the thermal properties of both fluid and wall. Due to Newton's law, " $h$ " is seen to evolve as $1 / \Theta_{\mathrm{w}}$.

Figures 10 and 11 highlight the evolution of the convective exchange coefficient " $\mathrm{h}$ ". It is clearly seen that increasing the particle volume fraction leads to a degradation in the heat

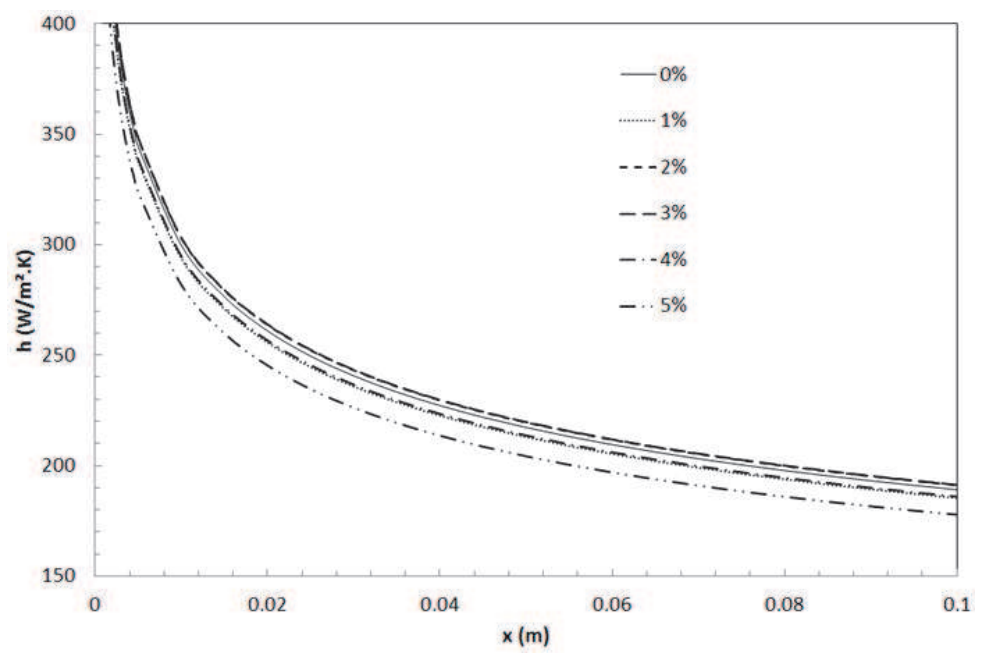

Fig. 10. Heat transfer coefficient at wall for $\mathrm{CuO} /$ water nanofluid 
transfer enhancement. This result appears to be consistent with that from a previous published work (Putra et al., 2003) in which the authors mentioned that, unlike conduction or forced convection, a systematic and definite deterioration in free convective heat transfer has been found while using nanofluids. This apparent paradoxical behaviour when increasing the particle volume fraction can be explained as follows. Adding solid nanoparticles is expected to increase the thermal conductivity, thus resulting in higher heat transfer.

However, an augmentation of the particle volume fraction also increases the mixture viscosity. For the natural convection flow of this study, it appears that the effect of increased viscosity is dominant over the increase of thermal conductivity.

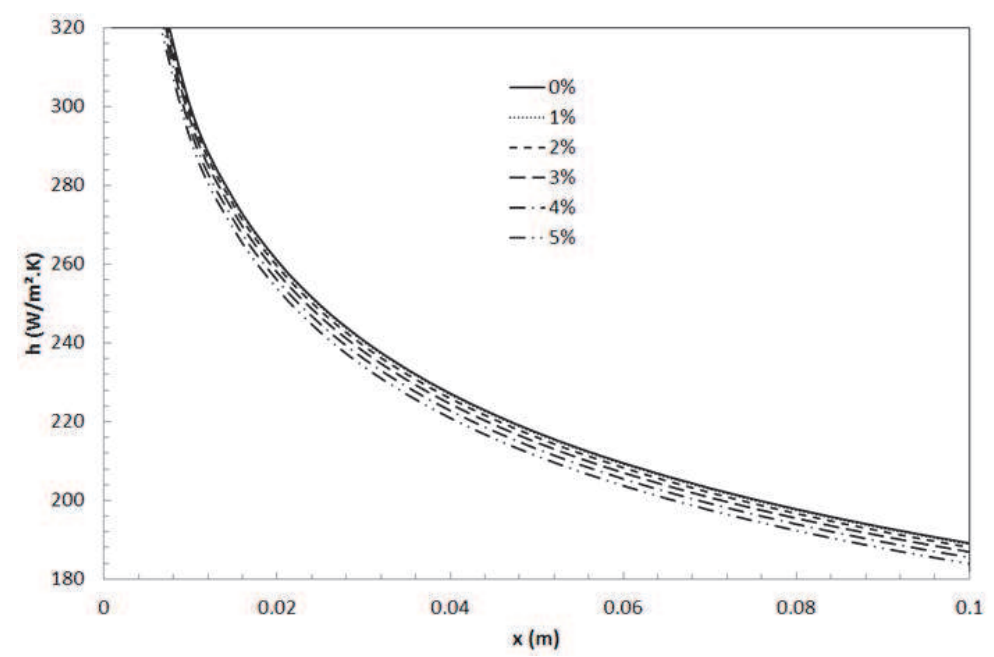

Fig. 11. Heat transfer coefficient at the wall for Alumina / water nanofluid

\subsection{Forced convection}

We consider now the external boundary layer flow past a semi-infinite flat plate in a thermal equilibrium state, as defined in Figure 1. The flow is laminar and assumed to be incompressible. Its thermal properties are considered as constant. A uniform heat flux density whose value is $1000 \mathrm{~W} / \mathrm{m}^{2}$ is applied at the upper surface of the plate. The velocity of the free external stream is $1 \mathrm{~m} / \mathrm{s}$.

Like the natural convection problem, we first focuse the dynamical features of the two nanofluid flows and finally consider the heat transfer characteristics, varying the particle volume fraction.

In figures 12 and 13 are presented the steady velocity boundary layer thickness along the wall, for the two tested nanofluids (CuO/Water andAlumina/water), in the range of Newtonian behaviour, namely for small values of particle volume fraction $\phi<5 \%$.

Because the viscosity of the mixture increases with the particle volume fraction, it is seen that the thickness of the boundary layer increases. This phenomenon is similar to that observed with the free convection case. Moreover, this increase in thickness is also found to be more important with the $\mathrm{CuO} /$ water nanofluid. 


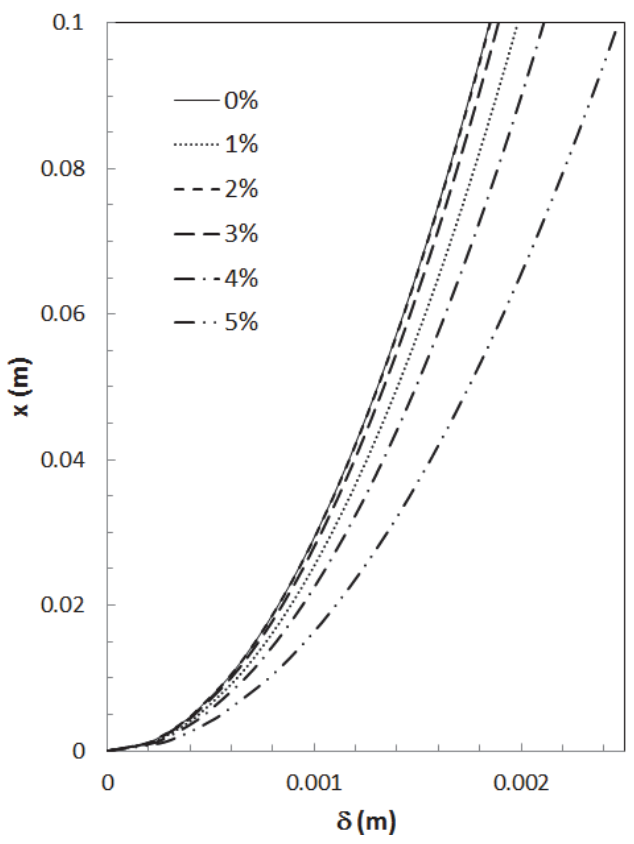

Fig. 12. Velocity boundary layer for $\mathrm{CuO} /$ water nanofluid

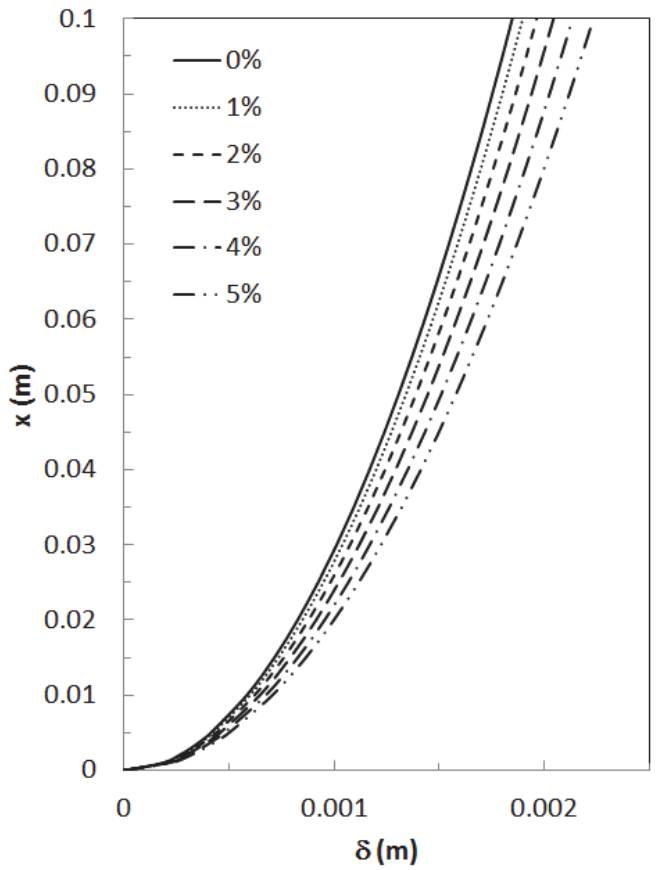

Fig. 13. Velocity boundary layer for Alumina / water nanofluid 
Consequently, the velocity profiles drawn in Figures 14 and 15 seem to follow this trend with respect to the volumetric flow rate conservation law. It is the reason why in the neighborhood of the wall, the velocity decreases with the particle volume fraction. This diminution is also more pronounced for the $\mathrm{CuO} /$ water nanofluid.

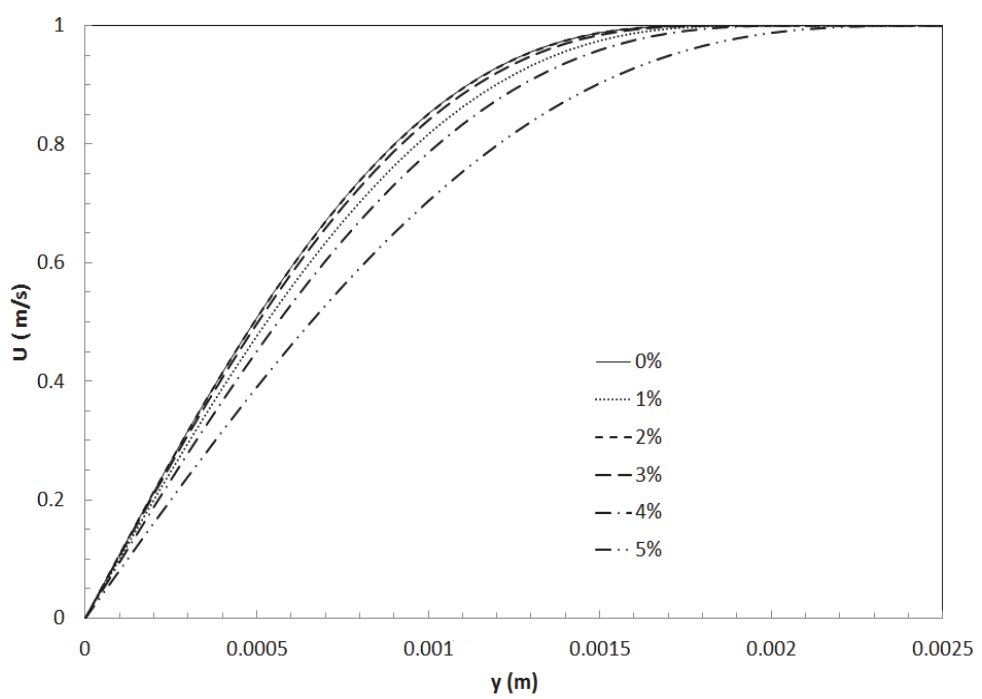

Fig. 14. Velocity profiles at $\mathrm{x}=0.1 \mathrm{~m}$ abscissa for $\mathrm{CuO} /$ water nanofluid

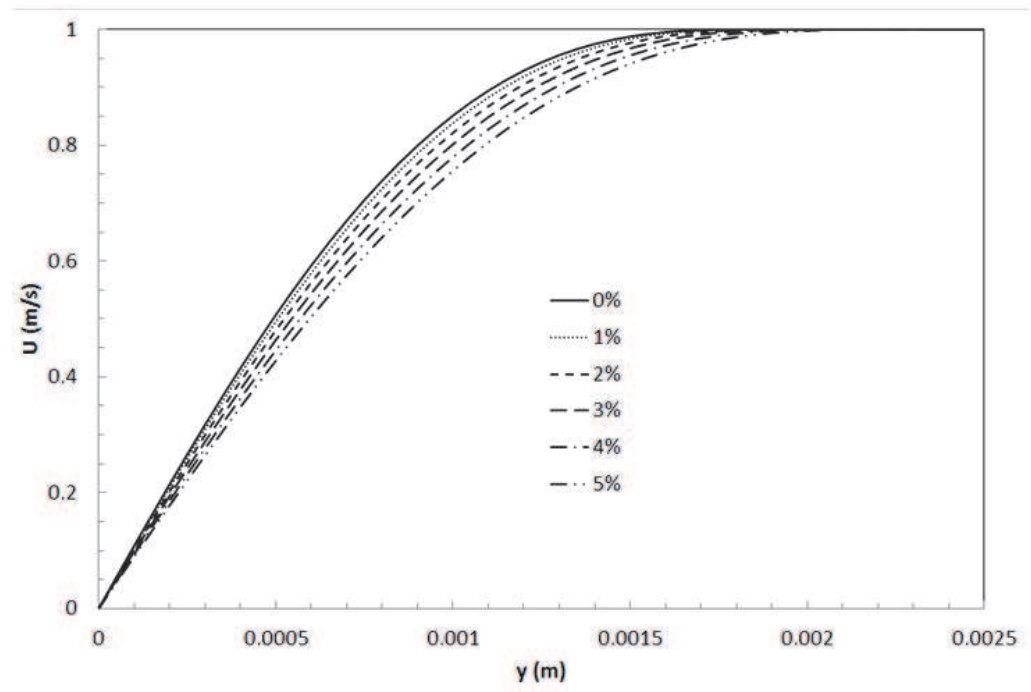

Fig. 15. Velocity profiles at $x=0.1 \mathrm{~m}$ abscissa for Alumina / water nanofluid 
The temperature profiles have been drawn for the two nanofluids at a given abscissa within the thermal boundary layer thickness. Globally, the temperature is seen to increase in the boundary layer when the particle volume fraction increases as shown in Figures 16 and 17.

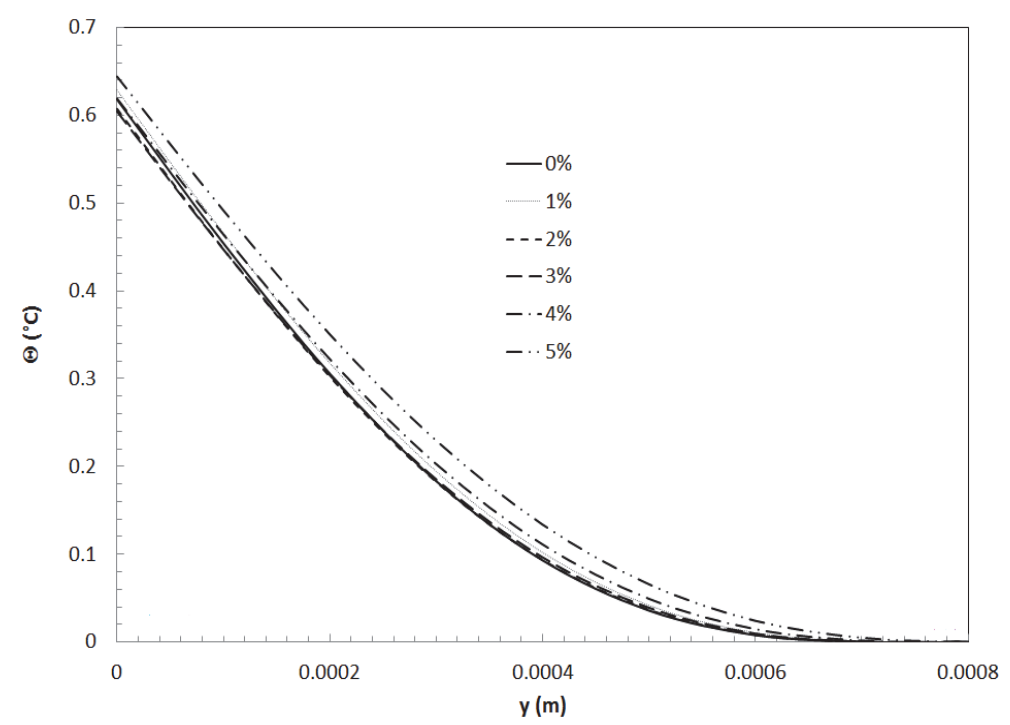

Fig. 16. Temperature profiles at $\mathrm{x}=0.1 \mathrm{~m}$ abscissa for $\mathrm{CuO} /$ water nanofluid

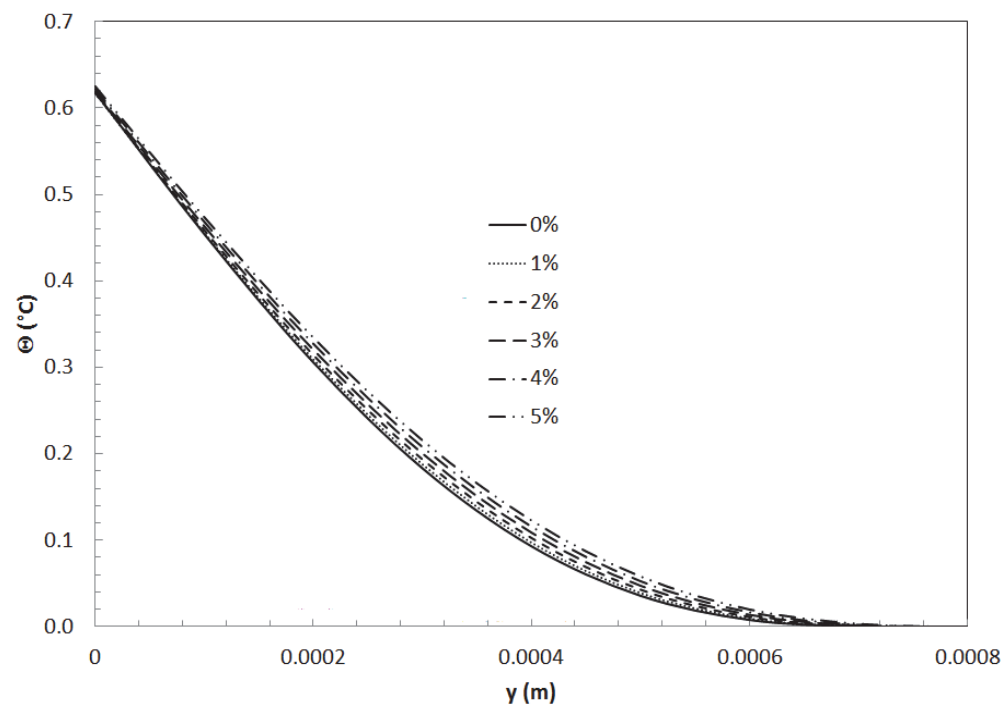

Fig. 17. Temperature profiles at $x=0.1 \mathrm{~m}$ abscissa for Alumina / water nanofluid

From both velocity and thermal parameters, we have chosen to access the thermal flow rate defined in Eq. 20. 
This parameter, drawn in Figures 18 and 19, which is calculated within the thermal boundary layer, evolves linearly along the wall. Strong differences are observed with the variation of the particle volume fraction.

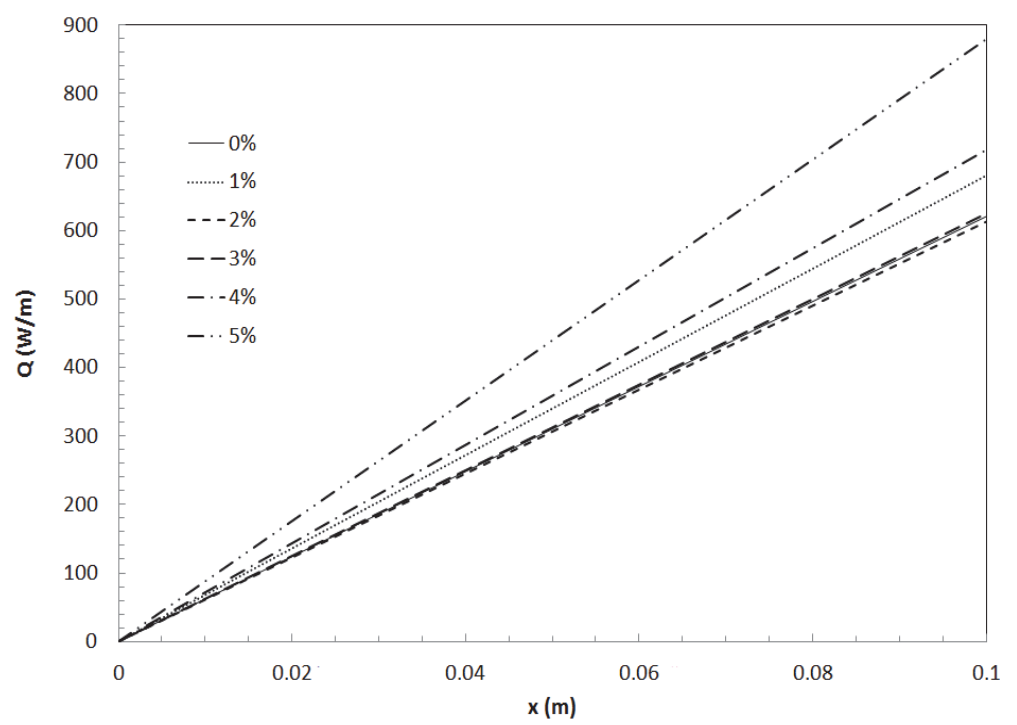

Fig. 18. Thermal flow rate for $\mathrm{CuO} /$ water nanofluid

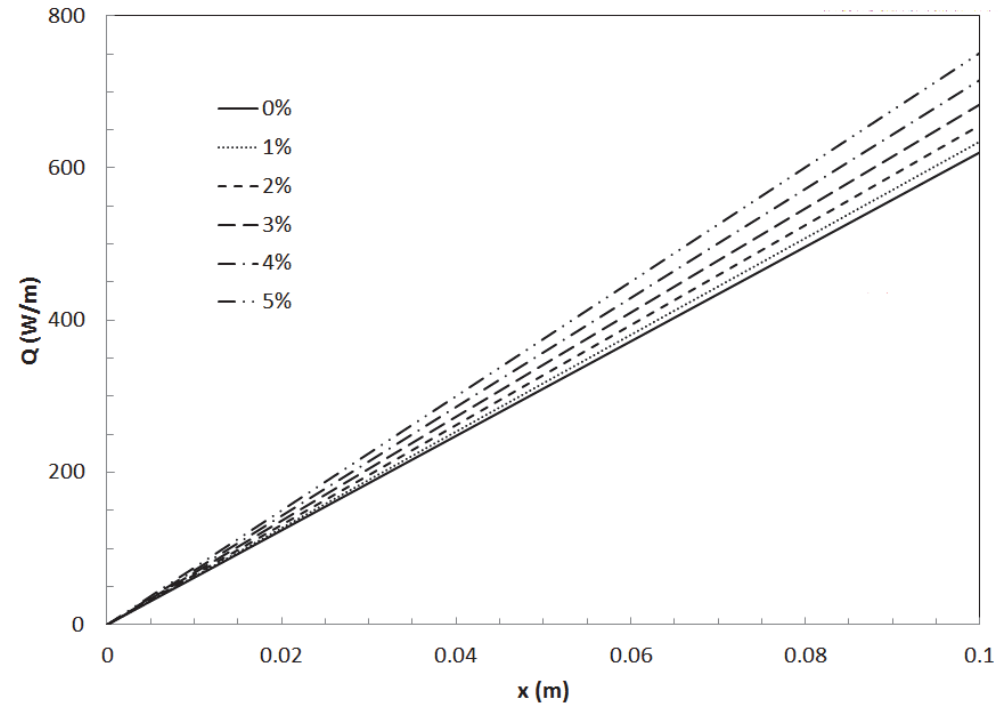

Fig. 19. Thermal flow rate for Alumina / water nanofluid 
To have a quantitative idea on how the thermal flow rate evolves with the particle volume fraction, the parameter $\varepsilon_{\mathrm{st}}$ is introduced :

$$
\varepsilon_{t h}=\left(\frac{Q_{t h n f}}{Q_{t h}}-1\right) * 100
$$

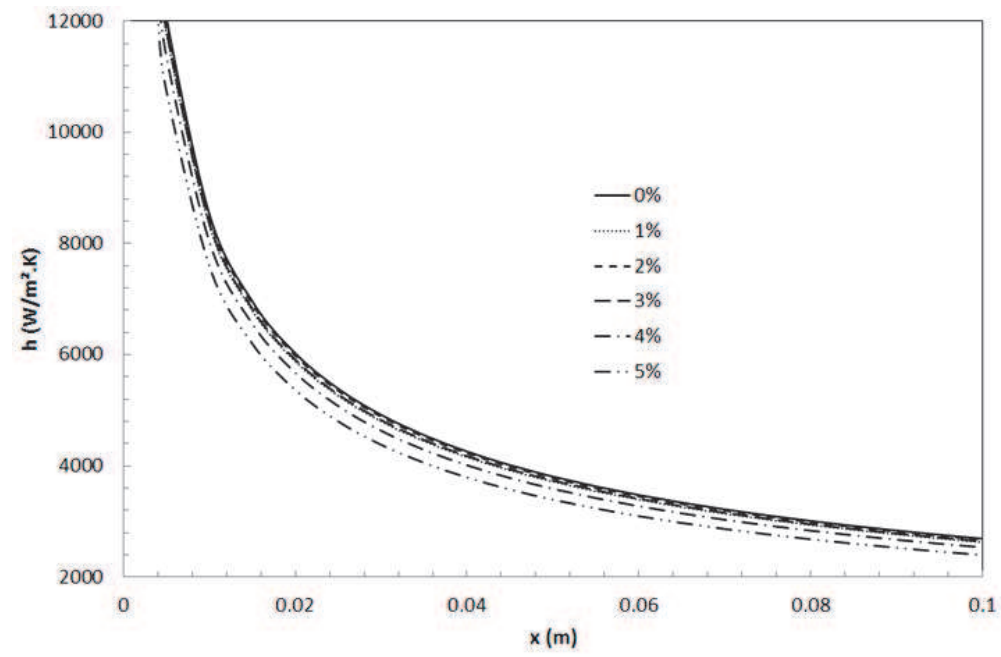

Fig. 20. Heat transfer coefficient at wall for $\mathrm{CuO} /$ water nanofluid

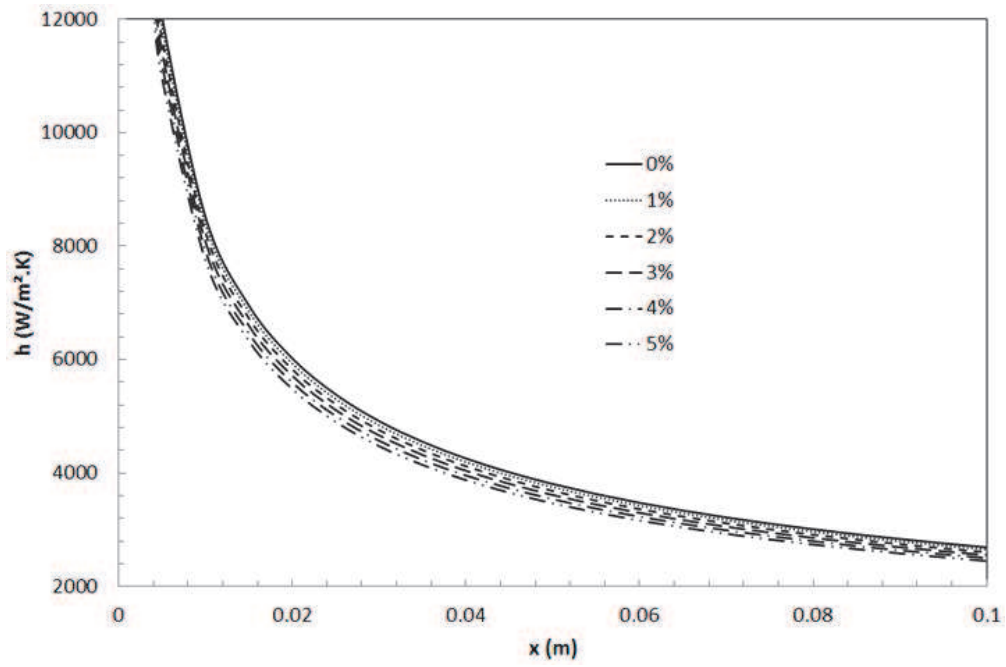

Fig. 21. Heat transfer coefficient at wall for Alumina / water nanofluid

Table 4 summarizes the evolution of this parameter with the particle volume fraction, for both nanofluids, traducing both heat and mass transfer in forced convection. It clearly appears that the thermal flow rate is strongly $\phi$ dependent. 
In comparison with the reference base fluid case, an enhancement in the thermal flow rate is observed, up to $42 \%$ for the $\mathrm{CuO} /$ water nanofluid and $21 \%$ for the Alumina/water nanofluid.

\begin{tabular}{|c|c|c|c|c|c|c|}
\hline & \multicolumn{3}{|c|}{$\mathrm{CuO} /$ water nanofluid } & \multicolumn{3}{c|}{ Alumina / water nanofluid } \\
\hline $\begin{array}{c}\text { Volume } \\
\text { fraction } \\
(\%)\end{array}$ & $\operatorname{Pr}$ & $\Delta$ & $\varepsilon_{\text {th }}$ & $\operatorname{Pr}$ & $\Delta$ & $\varepsilon_{\text {th }}$ \\
\hline 0 & 6.984 & 0.402 & $0.00 \%$ & 6.984 & 0.402 & $0.00 \%$ \\
\hline 1 & 8.006 & 0.383 & $9.64 \%$ & 7.222 & 0.397 & $2.28 \%$ \\
\hline 2 & 6.860 & 0.404 & $-1.23 \%$ & 7.586 & 0.390 & $5.72 \%$ \\
\hline 3 & 7.058 & 0.400 & $0.69 \%$ & 8.058 & 0.382 & $10.13 \%$ \\
\hline 4 & 8.662 & 0.373 & $15.66 \%$ & 8.623 & 0.374 & $15.31 \%$ \\
\hline 5 & 11.709 & 0.337 & $41.72 \%$ & 9.267 & 0.365 & $21.03 \%$ \\
\hline
\end{tabular}

Table 4. Nanofluids properties in forced convection

\section{Conclusion}

In the present study, both free convection and forced convection problems of Newtonian $\mathrm{CuO} /$ water and alumina/water nanofluids over semi-infinite plates have been investigated from a theoretical viewpoint, for a range of nanoparticle volume fraction up to $5 \%$. The analysis is based on a macroscopic modelling and under assumption of constant thermophysical nanofluid properties.

Whatever the thermal convective regime is, namely free convection or forced convection, it seems that the viscosity, whose evolution is entirely due to the particle volume fraction value, plays a key role in the mass transfer. It is shown that using nanofluids strongly influences the boundary layer thickness by modifying the viscosity of the resulting mixture leading to variations in the mass transfer in the vicinity of walls in external boundary-layer flows. It has been shown that both viscous boundary layer and velocity profiles deduced from the Karman-Pohlhausen analysys, are highly viscosity dependent.

Concerning the heat transfer, results are more contrasted. Whatever the nanofluid, increasing the nanoparticle volume fraction leads to a degradation in the external free convection heat transfer, compared to the base-fluid reference. This confirms previous conclusions about similar analyses and tends to prove that the use of nanofluids remains illusory in external free convection.

A contrario, the external forced convection analyses shows that the use of nanofluids is a powerful mean to modify and enhance the heat transfer, and the thermal flow rate which are strongly dependent of the nanoparticle volume fraction.

\section{Nomenclature}

$\mathrm{Cp} \quad$ specific heat capacity $\mathrm{J} \cdot \mathrm{kg}^{-1} \cdot \mathrm{K}^{-1}$

$\mathrm{g}$ acceleration of the gravity $\mathrm{m} \cdot \mathrm{s}^{-2}$

$\mathrm{h} \quad$ heat transfer coefficient W.m-2.K-1 


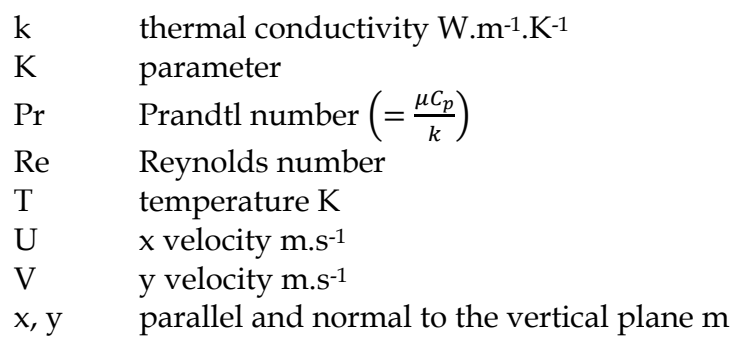

\subsection{Greek symbols}

$\beta \quad$ coefficient of thermal expansion $\mathrm{K}^{-1}$

$\delta \quad$ dynamical boundary layer thickness $\mathrm{m}$

$\delta_{\mathrm{T}} \quad$ thermal boundary layer thickness $\mathrm{m}$

$\Delta \quad$ thermal to velocity layer thickness ratio

$\varepsilon, \Omega \quad$ parameters

$\phi \quad$ particle volume fraction $\%$

$\varphi \quad$ heat flux density W. $m^{-2}$

$v \quad$ kinematic viscosity $\mathrm{m}^{2} \cdot \mathrm{s}^{-1}$

$\rho \quad$ density kg. $\mathrm{m}^{-3}$

$\Psi \quad$ streamline function $\mathrm{s}^{-1}$

$\Theta \quad$ temperature ${ }^{\circ} \mathrm{C}$

\subsection{Subscripts}

bf base-fluid

nf nanofluid

$\mathrm{p}$ nanoparticle

th thermal

w wall

\section{References}

Ben Mansour, R., Galanis, N. \& Nguyen, C.T., (2007). Effect of uncertainties in physical properties on forced convection heat transfer with nanofluids. Appl. Therm. Eng. Vol. 27 (2007) pp.240-249.

Brinkman, H.C. (1952). The viscosity of concentrated suspensions and solutions. J. Chem. Phys. Vol. 20 (1952) pp. 571-581.

Fohanno, S., Nguyen, C.T. \& Polidori, G. (2010). Newtonian nanofluids in convection, In: Handbook of Nanophysics (Chapter 30), K. Sattler (Ed.), CRC Press, ISBN 978-1420075-44-1, New-York, USA

Kakaç, S. \& Yener, Y., Convective heat transfer, Second Ed., CRC Press, Boca Raton, 1995.

Keblinski, P., Prasher, R. \& Eapen, J. (2008). Thermal conductance of nanofluids: is the controversy over? J. Nanopart. Res. Vol.10. pp.1089-1097.

Khanafer, K., Vafai, K., Lightstone, M., (2003). Buoyancy-driven heat transfer enhancement in a two-dimensional enclosure using nanofluids. Int. J. Heat Mass Transf. Vol. 46 pp.3639-3653. 
Maïga, S.E.B. Palm, S.J., Nguyen, C.T., Roy, G. \& Galanis, N. (2005). Heat transfer enhancement by using nanofluids in forced convection flows. Int. J. Heat Fluid Flow Vol. 26 (2005) pp.530-546.

Maïga S.E.B., Nguyen C.T., Galanis N., Roy G., Maré T., Coqueux M., Heat transfer enhancement in turbulent tube flow using $\mathrm{Al} 2 \mathrm{O} 3$ nanoparticle suspension, Int. J. Num. Meth. Heat Fluid Flow, 16- 3 (2006) 275-292.

Mintsa H.A., Roy G., Nguyen C.T., Doucet D., New temperature dependent thermal conductivity data for water-based nanofluids, Int. J. of Thermal Sciences, 48 (2009) 363-371.

Murshed, S.M.S., Leong, K.C., Yang, C. (2005). Enhanced thermal conductivity ofTiO2ewater based nanofluids. Int. J. Therm. Sci. Vol.44 pp.367-373.

Nguyen C.T., Desgranges F., Roy G., Galanis N., Maré T., Boucher S., Mintsa H. Angue, Temperature and particle-size dependent viscosity data for water-based nanofluids - Hysteresis phenomenon, International Journal of Heat and Fluid Flow, 28 (2007) 1492-1506.

Nguyen, C.T., Galanis, N., Polidori, G., Fohanno, S., Popa, C.V. \& Le Bechec A. (2009). An experimental study of a confined and submerged impinging jet heat transfer using Al2O3-water nanofluid, International Journal of Thermal Sciences, Vol. 48, pp.401-411

Pak B. C., Cho Y. I., Hydrodynamic and heat transfer study of dispersed fluids with submicron metallic oxide particles, Exp. Heat Transfer, 11- 2 (1998) 151-170.

Padet, J. Principe des transferts convectifs, Ed. polytechnica, Paris, 1997.

Polidori, G., Rebay, M. \& Padet J. (1999). Retour sur les résultats de la théorie de la convection forcée laminaire établie en écoulement de couche limite 2D. Int. J. Therm. Sci., Vol. 38 pp.398-409.

Polidori, G., Mladin, E.-C. \& de Lorenzo, T. (2000). Extension de la méthode de KármánPohlhausen aux régimes transitoires de convection libre, pour Pr $>0,6$. ComptesRendus de l'Académie des Sciences, Vol.328, Série IIb, pp. 763-766

Polidori, G. \& Padet, J. (2002). Transient laminar forced convection with arbitrary variation in the wall heat flux. Heat and Mass Transfer, Vol.38, pp. 301-307

Polidori, G., Popa, C. \& Mai, T.H. (2003). Transient flow rate behaviour in an external natural convection boundary layer. Mechanics Research Communications, Vol.30, pp. 615-621.

Polidori, G., Fohanno, S. \& Nguyen, C.T. (2007). A note on heat transfer modelling of Newtonian nanofluids in laminar free convection. Int. J. Therm. Sci. Vol.46 (2007) pp. 739-744.

Popa, C.V., Fohanno, S., Nguyen, C.T. \& Polidori G. (2010). On heat transfer in external natural convection flows using two nanofluids, International Journal of Thermal Sciences, Vol. 49, pp. 901-908

Putra, N., Roetzel, W. \& Das S.K. (2003). Natural convection of nanofluids. Heat Mass Transfer, Vol.39 pp. 775-784.

Varga, C., Fohanno, S. \& Polidori G. (2004). Turbulent boundary-layer buoyant flow modeling over a wide Prandtl number range. Acta Mechanica Vol.172. pp.65-73.

Xuan, Y. \& Li, Q. (2000). Heat transfer enhancement of nanofluids. Int. J. Heat Fluid Flow, Vol.21 (2000) pp.58-64.

Xuan, Y. \& Roetzel, W. 2000. Conceptions for heat transfer correlation of nanofluids. Int. J. Heat Mass Transfer, Vol.43 pp.3701-3707. 
Wang, X.-Q. \&, Mujumdar, A.S. (2007). Heat transfer characteristics of nanofluids : a review. Int. J. Thermal Sciences vol.46 pp.1-19.

Zhou S.-Q., Ni R., Measurement of specific heat capacity of water-based Al2O3 nanofluid, Applied Physics Letters, 92 (2008) 093123. 


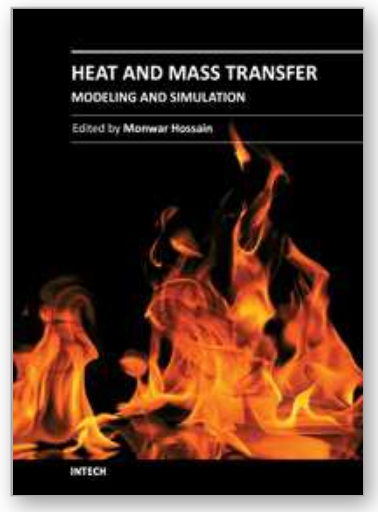

\author{
Heat and Mass Transfer - Modeling and Simulation \\ Edited by Prof. Md Monwar Hossain
}

ISBN 978-953-307-604-1

Hard cover, 216 pages

Publisher InTech

Published online 22, September, 2011

Published in print edition September, 2011

This book covers a number of topics in heat and mass transfer processes for a variety of industrial applications. The research papers provide advances in knowledge and design guidelines in terms of theory, mathematical modeling and experimental findings in multiple research areas relevant to many industrial processes and related equipment design. The design of equipment includes air heaters, cooling towers, chemical system vaporization, high temperature polymerization and hydrogen production by steam reforming. Nine chapters of the book will serve as an important reference for scientists and academics working in the research areas mentioned above, especially in the aspects of heat and mass transfer, analytical/numerical solutions and optimization of the processes.

\title{
How to reference
}

In order to correctly reference this scholarly work, feel free to copy and paste the following:

Catalin Popa, Guillaume Polidori, Ahlem Arfaoui and Stéphane Fohanno (2011). Heat and Mass Transfer in External Boundary Layer Flows Using Nanofluids, Heat and Mass Transfer - Modeling and Simulation, Prof. Md Monwar Hossain (Ed.), ISBN: 978-953-307-604-1, InTech, Available from:

http://www.intechopen.com/books/heat-and-mass-transfer-modeling-and-simulation/heat-and-mass-transferin-external-boundary-layer-flows-using-nanofluids

\section{INTECH}

open science | open minds

\author{
InTech Europe \\ University Campus STeP Ri \\ Slavka Krautzeka 83/A \\ 51000 Rijeka, Croatia \\ Phone: +385 (51) 770447 \\ Fax: +385 (51) 686166 \\ www.intechopen.com
}

\author{
InTech China \\ Unit 405, Office Block, Hotel Equatorial Shanghai \\ No.65, Yan An Road (West), Shanghai, 200040, China \\ 中国上海市延安西路65号上海国际贵都大饭店办公楼 405 单元 \\ Phone: +86-21-62489820 \\ Fax: +86-21-62489821
}


(C) 2011 The Author(s). Licensee IntechOpen. This chapter is distributed under the terms of the Creative Commons Attribution-NonCommercialShareAlike-3.0 License, which permits use, distribution and reproduction for non-commercial purposes, provided the original is properly cited and derivative works building on this content are distributed under the same license. 